\title{
"Suicide shall cease to be a crime": suicide and undetermined death trends 1970-2000 before and after the decriminalization of suicide in Ireland 1993
}

\author{
Mugtaba Osman $^{1} \cdot$ Andrew C. Parnell ${ }^{2} \cdot$ Clifford Haley $^{1}$
}

Received: 14 January 2016/Accepted: 9 May 2016/Published online: 17 May 2016

(C) Royal Academy of Medicine in Ireland 2016

\begin{abstract}
Introduction Suicide is criminalized in more than 100 countries around the world. A dearth of research exists into the effect of suicide legislation on suicide rates and available statistics are mixed.

Materials and methods This study investigates 10,353 suicide deaths in Ireland that took place between 1970 and 2000. Irish 1970-2000 annual suicide data were obtained from the Central Statistics Office and modelled via a negative binomial regression approach. We examined the effect of suicide legislation on different age groups and on both sexes. We used Bonferroni correction for multiple modelling. Statistical analysis was performed using the $\mathrm{R}$ statistical package version 3.1.2. The coefficient for the effect of suicide act on overall suicide deaths was -9.094 (95\% confidence interval (CI) -34.086 to 15.899 ), statistically non-significant $(p=0.476)$. The coefficient for the effect suicide act on undetermined deaths was statistically significant $(p<0.001)$ and was estimated to be -644.4 (95\% CI -818.6 to -469.9 ).

Conclusion The results of our study indicate that legalization of suicide is not associated with a significant increase in subsequent suicide deaths. However, undetermined death verdict rates have significantly dropped following legalization of suicide.
\end{abstract}

Mugtaba Osman

mugtabasulman@yahoo.co.uk

1 Department of Psychiatry, Letterkenny General Hospital, Letterkenny, Co. Donegal, Ireland

2 School of Mathematical Sciences, Insight: the National Centre for Data Analytics, University College Dublin, Belfield, Dublin, Ireland
Keywords Suicide $\cdot$ Criminal Law $\cdot$ Ethics $\cdot$ Legislation · Ireland

\section{Introduction}

In June 1993, suicide was decriminalized in Ireland [1]; as in other 58 countries around the world, most recently by India [2]. Suicide attempters are prosecuted in 45 countries [3] whose legislators argue that criminalization can prevent suicidal behaviour [4]. Nevertheless, legalization of suicide is thought to eliminate the social stigma associated with suicide, and therefore, ease the burden from family members [5]. A dearth of research exists into the effect of suicide legislation and available statistics are too mixed to support either viewpoint [6]. The effect of suicide decriminalization in seven countries was investigated by Lester some 12 years ago [7]. His pioneering work spanned 10 year suicide data and concluded that decriminalization was associated with an increase in "official" suicide rates. He conducted a 20 year linear time-series investigation and found no affect for suicide decriminalization act 1961 in New Zealand [8]. In a similar 20 year investigation legalization of suicide 1972 in Canada led to no increase in suicide rates [9]. A reduction in Suicide deaths was reported in Sri Lanka following decriminalization of suicide in 1998 by the parliament [10]. In this study, we built on the previous important work by modelling a 30 year long time-series of combined suicide deaths with undetermined deaths, using principled negative binomial model of the counts of suicide deaths. We aimed to take account of trends present before legalization of suicide, an issue that many previous studies addressed inadequately. 


\section{Method}

Irish 1970-2000 annual suicide data were obtained from the Central Statistics Office [11] and modelled via a negative binomial regression approach [12] including an offset term representing the yearly population [13]. We then quantified the effect of suicide decriminalization by including an indicator variable set to be non-zero only from the year 1993 onward, and included an interaction term between the year and the suicide legislation. We examined the effect of suicide legislation on different age groups and on both sexes. Bonferroni correction for multiple modelling implied that for a $5 \%$ significance level we require $P<0.00139$ [14]. We combined reported suicide deaths with undetermined deaths to give a better estimate of the total annual suicide deaths [15]. Furthermore, we conducted a sensitivity analysis using only the reported suicide deaths. Statistical analysis was performed using the $\mathrm{R}$ statistical package version 3.1.2 [16].

\section{Results}

Annual suicide deaths in Ireland were rising during the 1970-2000 period (see Fig. 1). A total of 10,353 deaths were attributed to suicide. The highest overall suicide deaths was 517, and was recorded in 1998. The total mean number of suicides prior to decriminalization act was 216.5 deaths a year. This increased to 448.7 suicide deaths a year after 1993.
The ratio between male and female suicide deaths fluctuated between 1.85 in the year 1977 and 5.50 in the year 1970, the mean was 3.33 (Standard Deviation $\mathrm{SD}=1.05)$. The mean for the male-to-female suicide ratio jumped significantly from 3.05 prior to suicide decriminalization to 4.32 afterwards $(t=3.60, p=0.004)$.

Breaking suicide deaths by age group, prior to 1993 , the mean for deaths in children below the age of 15 was 1.25 suicides per year and increased to 3.14 suicides per year after 1993. The corresponding figures for the 15-34 years age groups were 81.04 (prior to 1993) and 205.4 (after 1993); whereas for the 35-65 years age group, the average annual suicide deaths (prior to 1993) was 104.6 and (after 1993) was 198.3 deaths a year. For those above 65-yearsold, the mean yearly suicide deaths before suicide was legalized was 29.62 and increased afterwards to 41.86 suicide deaths per annum.

Upon investigating the effect of legalization of suicide on the overall suicide deaths (see Table 1), the coefficient for the suicide act was $-9.094(95 \%$ CI -34.086 to $15.899)$, statistically non-significant $(p=0.476)$. Similarly, the coefficient for the interaction term in the model was 0.002 (95\% CI -0.004 to 0.009 ) which was also statistically not significant $(p=0.476)$. This suggests that there was no change in the rate of suicide occurrence after 1993. The odds for the rate of death by suicide for the total Irish population following legislation of suicide were calculated as 1.002 (95\% CI 0.996-1.009). This translates to an increase in the rate of suicide deaths by $0.2 \%(95 \% \mathrm{CI}$ -0.4 to $0.9 \%$ ). Across the age groups the rate of suicide

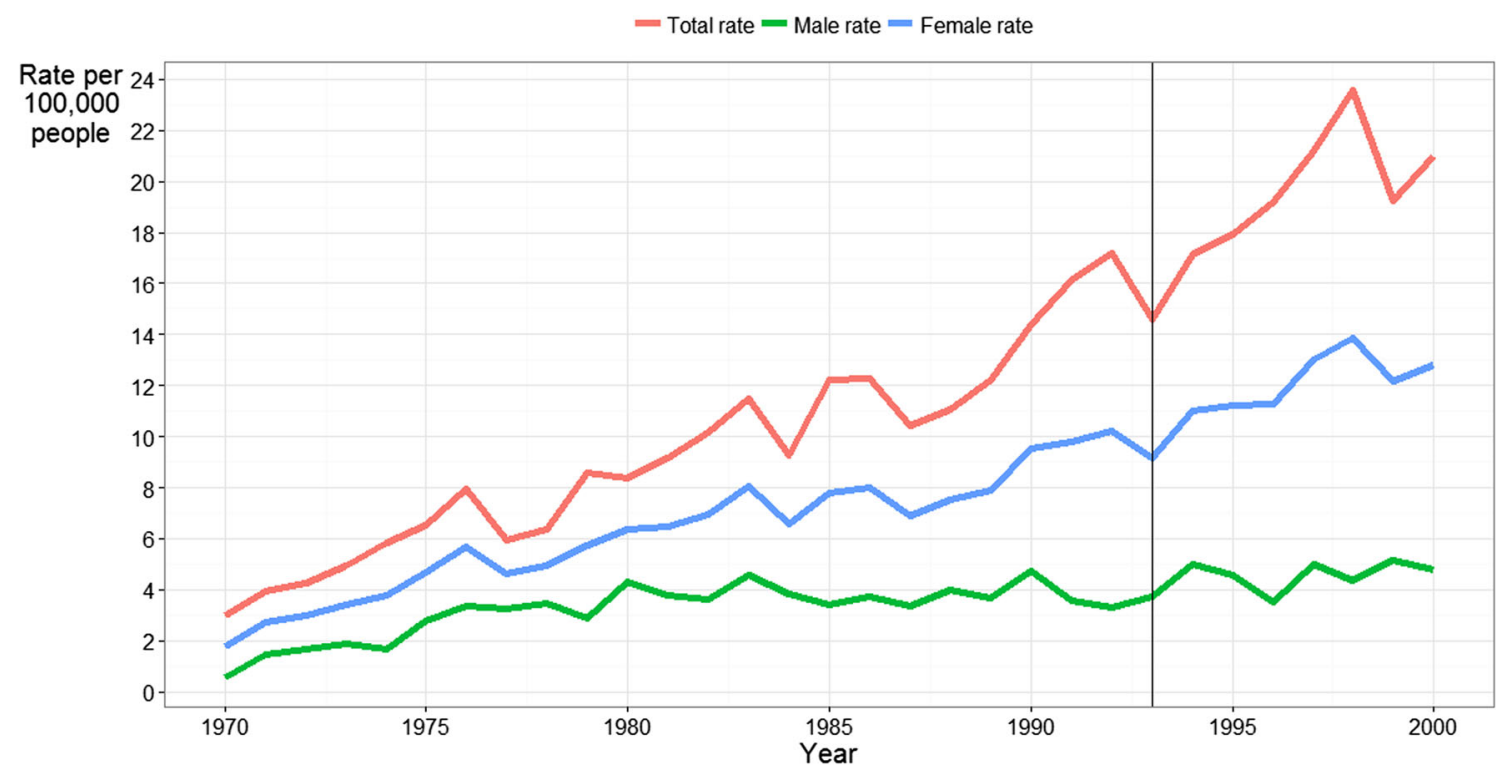

Fig. 1 The 1970-2000 annual suicide rates per 100,000 of the population in Ireland 
Table 1 Effect of the suicide decriminalization on combined undetermined and reported suicide deaths

\begin{tabular}{|c|c|c|c|c|c|c|}
\hline Age category & Suicide act & SE & $p$ value & Time $\times$ act interaction & SE & $p$ value \\
\hline \multicolumn{7}{|l|}{ Overall } \\
\hline $0-14$ & -29.394 & 180.26 & 0.87 & 0.008 & 0.045 & 0.867 \\
\hline $15-24$ & -50.002 & 18.078 & 0.153 & 0.013 & 0.005 & 0.152 \\
\hline $25-34$ & -31.544 & 17.275 & 0.068 & 0.008 & 0.004 & 0.068 \\
\hline $35-44$ & -35.086 & 22.964 & 0.127 & 0.009 & 0.006 & 0.126 \\
\hline $45-54$ & 6.03 & 31.036 & 0.846 & -0.002 & 0.008 & 0.839 \\
\hline $55-64$ & -32.56 & 39.507 & 0.41 & 0.008 & 0.01 & 0.412 \\
\hline $65-74$ & -105.297 & 143.286 & 0.462 & 0.053 & 0.072 & 0.464 \\
\hline $75-$ & -0.607 & 39.23 & 0.988 & 0 & 0.01 & 0.989 \\
\hline Total & -9.094 & 12.751 & 0.476 & 0.002 & 0.003 & 0.476 \\
\hline \multicolumn{7}{|l|}{ Gender } \\
\hline Men & -29.394 & 180.26 & 0.87 & 0.008 & 0.045 & 0.867 \\
\hline Women & -50.002 & 18.078 & 0.153 & 0.013 & 0.005 & 0.152 \\
\hline Total & -9.094 & 12.751 & 0.476 & 0.002 & 0.003 & 0.476 \\
\hline \multicolumn{7}{|l|}{ Undetermined } \\
\hline Men & -648.7 & 90.69 & $<0.001$ & 0.325 & 0.045 & $<0.001$ \\
\hline Women & -706.8 & 125.8 & $<0.001$ & 0.354 & 0.063 & $<0.001$ \\
\hline Total & -644.4 & 89.01 & $<0.001$ & 0.161 & 0.022 & $<0.001$ \\
\hline \multicolumn{7}{|c|}{ Reported suicides } \\
\hline Men & 80.786 & 33.446 & 0.0157 & -0.041 & 0.017 & 0.0156 \\
\hline Women & 80.961 & 70.677 & 0.252 & -0.041 & 0.035 & 0.251 \\
\hline Total & 76.83 & 39.126 & 0.0496 & -0.019 & 0.01 & 0.0492 \\
\hline
\end{tabular}

has showed no statistically significant change following decriminalization of suicide.

As to the effect of suicide legalization on male suicides (see Table 1), an overall rise in suicide rate by $0.4 \%$ was noted (95\% CI -2.1 to $2.9 \%$ ), not significant statistically $(p=0.775)$. On the other hand (see Table 1), females recorded an upsurge in the rate of suicide deaths by $1.7 \%$ (95\% CI -3.4 to $7.2 \%$ ), although the effect size was slightly more impressive, it was still statistically insignificant $(p=0.521)$. Breaking down the gender variables by age classes, the odds varied between 0.680 and 1.109 for females and between 0.785 and 1.034 for males, with none of the changes in suicide deaths rates being statistically significant.

Focusing the analysis on the reported suicides alone (see Table 1), the overall effect for the suicide act was a positive rise, the coefficient was 67.83 (95\% CI 0.14-153.52), a wide confidence interval, that is not significant statistically ( $p=0.0492$ ) with the penalty posed by the Bonferroni correction. Examining men and women separately, the effect of the suicide act on female reported suicide deaths was not statistically significant $(p=0.251)$. For men, the ( $p=0.0156)$ was still not significant at the level required following Bonferroni correction.

However, examining the effect of suicide legalization act on the rates of undetermined deaths indicated a statistically significant reduction after 1993. The coefficient for the suicide act was -644.4 (95\% CI -818.6 to -469.9$)$, which was statistically significant $(p<0.001)$. Additionally, the coefficients for the effect of suicide act on undetermined deaths rates for men and women were statistically significant with $95 \%$ CI of $(-826.45$ to -470.95$)$, and ( -953.37 to -460.23$)$, respectively.

\section{Discussion}

The results of our study indicate that legalization of suicide is, reassuringly and despite the slight $0.2 \%$ increase (0.4\% for males and $1.7 \%$ for females), not associated with a statistically significant increase in the subsequent rate of suicide deaths. Moreover, slight and insignificant reduction in suicide deaths rates following 1993 legislation act was noted by $0.2 \%$ in the $45-54$ years old group, (5.2\% in females between 45 and 54 years of age, $4.2 \%$ in females aged 55-64, 3.8 \% in males aged 55-64, $0.8 \%$ in males aged $65-74$, and $1.7 \%$ in males above 75 -yearsold). Our study provides further support to the global/international campaign for decriminalization of suicide. These results may be used as an argument for those lawmakers seeking to destigmatize suicide mortality through decriminalizing suicidal behaviour. This can, undoubtedly, be furthered by other suicide prevention campaigns and programmes. 
Our study revealed the significantly negative effect of suicide decriminalization on the rates of undetermined deaths. The many demographic similarities between undetermined and suicide deaths have motivated researchers to expressed concerns regarding the misclassification of suicide deaths as undetermined [17]. Many amalgamate them when studying suicide rates [18]. Arguably, the Suicide act 1993 can be regarded as having removed restrictions on coroners to return a verdict of death by suicide, therefore, increasing the reported deaths by suicide after 1993 [19]. This has significant implication into suicide research specifically research investigating the effect of changes in legislation. Previous studies, notably, attempted to quantify the effect of suicide legalization on the reported suicide deaths alone [79]. The conclusions of such studies could have been improved greatly should data on undetermined deaths, if available, were included in the analysis.

To our knowledge, our study is first to explore the effect of decriminalization of suicide on each gender separately. Despite the study strength of taking account of undetermined deaths, an important limitation to this study is the reliance on registered causes of deaths. The Interim report of the National Task Force on Suicide has indicated that a margin of error of just $<5 \%$ is present in relation to the accuracy of data on suicide deaths in Ireland [20]. This has to be taken into account when the results of our study are interpreted. Moreover, the effect of suicide legislation on suicidal behaviour, which may not have resulted in death, remains beyond the scope of the current study. Another limitation that should be considered is that we were obliged to examine the 1993-2000 period only because we wanted to focus the analysis on the years that immediately followed suicide decriminalization. We attempted to avoid the additional effect posed by significant economic changes after the year 2000. Perhaps, other contemporary changes, unaccounted for by the present study, in suicide prevention policies may have their own effect on suicide deaths. One important suicide prevention landmark was the establishment of the National Task Force on Suicide in the mid to late 1990s. Some of its recommendations provided in its Interim report in September 1996 may have had an impact on suicide through various intervention strategies, emphasis on training of General Practitioners and all members of Primary Care Teams, improving communication with voluntary organisations, and screening and treatment of mental illness in the community, hospital and prison settings [20].

\section{Conclusion}

We found no evidence of rise in suicide deaths in any of the age groups or either gender after suicide was decriminalized in Ireland in 1993. These results may be used as an argument for law-makers seeking to destigmatize suicide mortality through decriminalizing suicidal behaviour. However, significant reduction in undetermined deaths has occurred following suicide decriminalization in 1993 indicating increased tendency for returning a verdict of 'suicide death'. Future research in epidemiological changes in suicide should pay attention to the changes observed in rates of undetermined deaths.

Acknowledgments Very special thanks to Ms. Pamela O'Connor, librarian in Letterkenny General Hospital, for immense help and support during the process of preparing the manuscript.

\section{Compliance with ethical standards}

Funding No funding was received for this study.

Conflict of interest Dr Mugtaba Osman declares that he has no conflict of interest. Dr Andrew Parnell declares that he has no conflict of interest. Dr Clifford Haley declares that he has no conflict of interest.

Ethical approval This article does not contain any studies with human participants or animals performed by any of the authors.

\section{References}

1. Irish Statute Book. Available online from http://www.irish statutebook.ie/1993/en/act/pub/0011/print.html

2. Varshney M, Gupta R, Balhara YP (2015) Yes, India has done it: Decriminalization of suicide in India. Asian J Psychiatr 17:103

3. Mishara BL, Weisstub DN (2016) The legal status of suicide: a global review. Int J Law Psychiatr 44:54-74

4. Hjelmeland H, Kinyanda E, Knizek BL (2012) Mental health workers' views on the criminalization of suicidal behaviour in Uganda. Med Sci Law 52(3):148-151 (CSO)

5. Latha KS, Geetha N (2004) Criminalizing suicide attempts: can it be a deterrent? Med Sci Law 44(4):343-347

6. Ranjan R, Kumar S, Pattanayak RD, Dhawan A, Sagar R (2014) (De-) criminalization of attempted suicide in India: a review. Industrial Psychiatry Journal. 23(1):4-9

7. Lester D (2002) Decriminalization of suicide in seven nations and suicide rates. Psychol Rep 91(3 Pt 1):898

8. Lester D (1993) Decriminalization of suicide in New Zealand and suicide rates. Psychol Rep 72(3 Pt 1):1050

9. Lester D (1992) Decriminalization of suicide in Canada and suicide rates. Psychol Rep 71(3 Pt 1):738

10. Knipe DW, Metcalfe C, Fernando R, Pearson M, Konradsen F, Eddleston M, Gunnell D (2014) Suicide in Sri Lanka 1975-2012: age, period and cohort analysis of police and hospital data. BMC Public Health 13(14):839

11. Central Statistics Office, Cork, Ireland. http://www.cso.ie/en/ releasesandpublications/birthsdeathsandmarriages/archive/annual reportsonmarriagesbirthsanddeathsinirelandfrom1864to2000/. Accessed on 24th May 2015

12. Bridge JA, Asti L, Horowitz LM, Greenhouse JB, Fontanella CA, Sheftall AH, Kelleher KJ, Campo JV (2015) Suicide trends among elementary school-aged children in the United States from 1993 to 2012. JAMA Pediatrics. doi:10.1001/jamapediatrics.2015.0465

13. Qian L, Tseng HF, Sy LS, Jacobsen SJ (2013) Confounder adjustment in vaccine safety studies: comparing three offset terms for case-centered approach. Vaccine 31(2):431-435 
14. Armstrong RA (2014) When to use the Bonferroni correction. Ophthalmic Physiol Opt 34(5):502-508

15. Platt S, Backett S, Kreitman N (1988) Social construction or causal ascription: distinguishing suicide from undetermined deaths. Soc Psychiatry Psychiatr Epidemiol 23(4):217-221

16. Paradis E (2005) R for beginners. Institut des Sciences de l'Evolution Press: Paris, France eBook available freely online from http://cran.r-project.org/doc/contrib/Paradis-rdebuts_en.pdf

17. Maniam T (1995) Suicide and undetermined violent deaths in Malaysia, 1966-1990: evidence for the misclassification of suicide statistics. Asia Pac J Public Health 8(3):181-185

18. Chang SS, Sterne JA, Lu TH, Gunnell D (2010) Hidden suicides amongst deaths certified as undetermined intent, accident by pesticide poisoning and accident by suffocation in Taiwan. Soc Psychiatry Psychiatr Epidemiol 45(2):143-152

19. Walsh D (2008) Suicide, attempted suicide and prevention in Ireland and elsewhere. HRB Overview Series 7. Health Research Board, Dublin, Ireland 2008. Page 24 chapter 3. The ascertainment of suicide in Ireland section 3.1

20. Department of Health and Children (1998) Report of the National Taskforce on Suicide. Government Publications. Dublin 2. Ireland. The full report is available on-line for free http://health.gov. ie/wp-content/uploads/2014/03/taskforce_suicide_1998.pdf, accessed on 24 April 2016 